\title{
Blasting Delay Pattern Development in the Light of Rockburst Prevention - Case Study from Polish Copper Mine
}

\author{
Piotr Mertuszka ${ }^{1, *}$, Marcin Szumny ${ }^{1}$, Andrzej Wawryszewicz ${ }^{2}$, Krzysztof Fuławka ${ }^{1}$, and \\ David Saiang ${ }^{3}$
}

${ }^{1}$ KGHM CUPRUM Ltd. Research \& Development Centre, 2-8 Sikorskiego, 53-659 Wrocław, Poland ${ }^{2}$ KGHM Polska Miedź S.A., Polkowice-Sieroszowice Mine, Kaźmierzów, 59-101 Polkowice, Poland

${ }^{3}$ Luleå University of Technology, SE-971 87 Luleå, Sweden

\begin{abstract}
In order to reduce the risk of induced seismicity related to underground mining, a number of preventive actions are applied in the form of passive and active prevention methods. The former are mainly of an organisational nature and their effectiveness is usually considered in the long term, while the active methods are mostly based on the detonation of explosives and are aimed to release the seismic energy accumulated in the rock mass. In this paper, modifications of the firing pattern aimed to concentrate the paraseismic vibrations while maintaining the appropriate excavation of the mining face has been verified on the basis of underground tests. The evaluation was based on fragmentation analysis. The obtained results confirmed, that the blasting pattern modifications related to the reducing of the face firing time do not cause significant differences in terms of the appropriate excavation of the mining face.
\end{abstract}

\section{Introduction}

Extraction of mineral deposits in underground mines is carried out at increasingly greater depths, which very often exceed $1,000 \mathrm{~m}$ below the surface. In many cases, the mining of such deposits is associated with difficult and complex geological and mining conditions, which pose a real risk to the crew. One of the most hazardous phenomena related to underground mining is the uncontrolled movement of rocks into the workings. This may include both the falling of rocks from the roof, as well as dynamic rock ejection into the workings resulting from rockburst. Such hazards occur frequently in mining worldwide and entail great risks for the personnel located in their impact zone [1-5]. The occurrence of rockbursts, which are caused by dynamic seismic events, is also relatively difficult to predict and control. In order to reduce this type of hazards, a number of methods are implemented. They can be divided into passive and active methods. Passive methods are primarily related to the selection of appropriate technology of mining and organisation of work. As for active methods, these are most frequently based on the blasting techniques and are aimed to release

\footnotetext{
* Corresponding author: pmertuszka@cuprum.wroc.pl
} 
the seismic energy accumulated in the rock mass. Depending on the form of the deposit and the adopted mining technology, active methods of seismic event prevention with the use of explosives may be applied as an element of the mining process itself, or as an independent process aimed at the rockburst prevention only.

The exploitation of deep deposits in underground mines is carried out using both mechanical mining systems (shearers, plows) as well as methods based on blasting techniques and explosives. However, it should be noted that explosives are also used in mechanical excavating systems for different types of auxiliary works, not directly related to the extraction of deposit. This could be the case in underground hard coal mines, in which the longwall mining methods are usually applied. When the mining is associated with the seismic hazards, blasting works in such mines are mostly utilised as an individual rockburst prevention method. These works, conducted as strain-release blasting normally consist of detonation of explosives in long blastholes located in the roof strata $[6,7,8]$. Other types of destress blasting are carried out in certain hard coal mines in China, where the rocks are fractured by explosives and fissures are created within the rock mass. The aim of these works is to change the stress level in the immediate surroundings of the workings [9].

In mines where explosives are used directly for deposit extraction, active rockburst prevention can be achieved both in the form of specialized works aimed to release the seismic energy accumulated in the rock mass manifested as a seismic event, or by applying of modified production drilling and firing patterns. Blasting technology which is designed for rock mass destressing only must be adapted to the local geological and mining conditions and the applied mining method in such a way, so that it may induce the stress relief but not disrupt the entire mining process. For this purpose, blastholes differing in length, diameter, delay sequence or the amount and type of explosives are used. Depending on the volume of the rock mass that has to be destressed, the length of blastholes can vary between several to several dozen metres with the mass of explosives even up to twenty tonnes [10,11, 12, 13]. When the rockburst prevention is based on production blasting, the modifications of these works are usually limited to the change in the scale, resulting in explosives mass increase. This can be done, among others, by increasing the number of fired faces, blastholes or the total explosive quantity.

Relatively high risk of rockburst hazard is associated with the exploitation of the copper ore deposit in Polish mines belonging to KGHM [14, 15]. This is related both to the geological structure of the deposit as well as to the depth of mining and the increasing minedout area. Extraction is conducted using the room-and-pillar mining method at a depth that locally exceeds $1,200 \mathrm{~m}$ below the surface. The thickness of the stratoidal ore body ranges from approximately $1 \mathrm{~m}$ up to even $26 \mathrm{~m}$, with 2-3 $\mathrm{m}$, on average. The ore body is composed of mineralised sandstone, shale and dolomite strata of varying thickness. The main roof strata consist of very hard dolomite with high thickness and strength, whereas the floor strata is typically formed from soft sandstone formations, what favours strong seismic events occurrences. Comparison of the seismic activity observed in the area of the Polish copper mines between 1990 and 2011 with the activity registered between 1965 and 1989 revealed an increase in the number of tremors by approximately 3.4 times, and an increase of the total annual energy emission from mining-induced tremors by approximately 9.5 times. The depth of mining, production level, mined-out area, adopted mining method and the low number of backfilled workings, were all identified as the main reasons affecting the seismic activity level [16]. Presently, the seismic activity has remained relatively low and stable, as shown by the lower total energy emission in the past years, even despite higher number of tremors, which amounts to approximately 5 thousand per year (fig. 1). The strong tremors, reaching seismic energy levels over $10^{6} \mathrm{~J}$, known as high-energy tremors, are quite often cause of rockbursts or other serious accidents and have particularly hazardous consequences. 


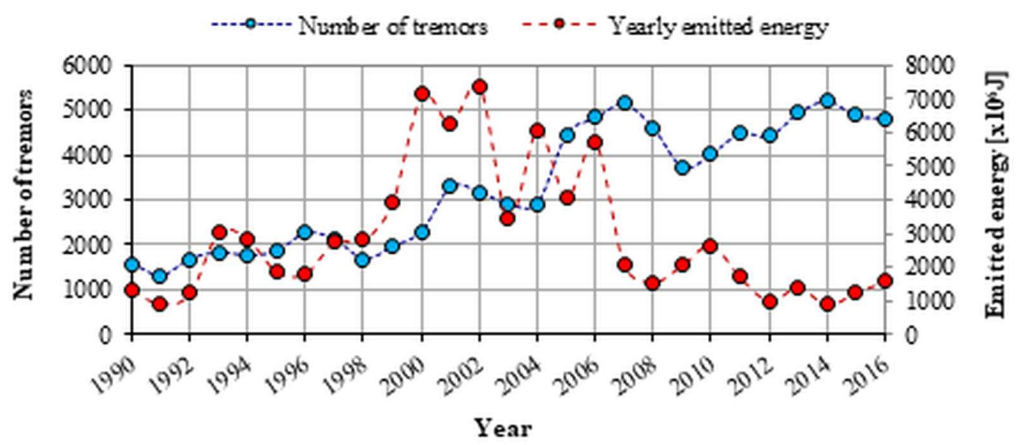

Fig. 1. Number and energy of tremors recorded between 1990 and 2016 in KGHM mines.

In order to improve the work safety conditions in Polish copper mines, a number of rockburst prevention methods are applied, both passive and active, which are aimed to reduce the seismic hazard [17]. Active rockburst prevention is applied primarily through the use of production blasting in the form of group blasting operations $[18,19]$. In the past, attempts with the long blastholes located in the roof strata were tested, similar to stress relief blasting implemented in Polish hard coal mines [20]. However, due to low efficiency, this method was abandoned.

The group blasting consists in firing of explosives at the same time in some dozen or even several dozen mining faces located in the undisturbed rock mass at a short distance from each other (fig. 2). This is aimed to amplify the energy of rock mass vibrations in a specific location in the main roof and release the elastic energy accumulated in the rock mass in the form of a provoked tremor. Another purpose of this kind of blasting is extraction of deposit, therefore the proper excavation and fragmentation of the rocks in the mining face is required. The preventive measure is then based on firing of greater number of faces, and thereby an increase of total explosive quantity. In recent years, the efficiency of active seismic hazard prevention methods in KGHM mines ranged from several to several dozen percent, depending on the considered mining panel. The greatest provocation efficiency was observed in the area of the Polkowice-Sieroszowice mine in 2015 and 2016, when respectively 74\% and $58 \%$ of all the tremors were induced by blasting operations. Currently, the provoking efficiency is estimated to be approximately $20-30 \%$, which is unsatisfactory [21].

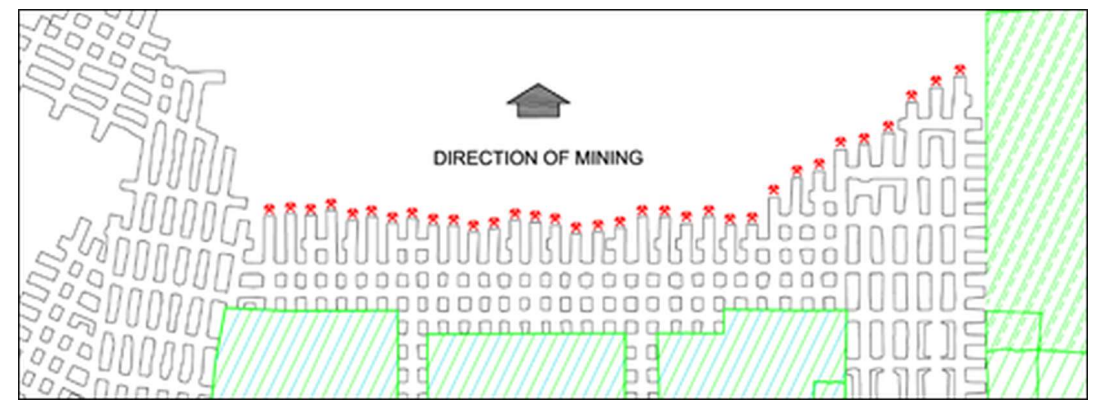

Fig. 2. Typical geometry of workings implemented for group destressing blasting.

Actions intended to induce the seismic event in a rock mass cannot disrupt the basic mining production cycle and it is therefore, important to ensure the proper excavation of the mining face. It is worth mentioning that approximately 70 tonnes of explosives loaded into several hundred faces is being fired every day in Polish copper mines, which indicates the great potential for work on new solutions within the scope of destress blasting. Non-electric 
delay detonators are currently used for explosive initiation. Their delays are specified in the blasting documentation. A correct firing sequence is required to ensure desired advance and fragmentation of output. In most cases, in Polish copper mines, detonators with a delay interval of $500 \mathrm{~ms}$ are used, except for the parallel cuts, where millisecond-delay detonators are employed. Depending on the size of the mining face, the entire firing sequence can last even up to 5-6 seconds. Assuming that the velocity of a seismic wave in a rock mass in the area of the KGHM mines is approximately 5,000 m/s [22], and considering the rock mass properties in terms of seismic waves damping, amplification of elastic wave is only possible with relatively short and precise delays. It is then assumed, that decreasing the time intervals would favor the likelihood of the occurrence of elastic wave interference.

In order to determine the feasibility of group blasting modification in terms of possible improvement of its efficiency, underground tests with the use of modified blasting patterns were carried out. The aim was to increase the seismic energy while maintaining the appropriate excavation of the mining face, both in terms of the advance as well as the rock fragmentation. The trials were conducted in selected workings of the PolkowiceSieroszowice mine. The regular drilling and blasting pattern applied in the considered mining panel was compared with the modified delay sequence pattern. The Authors' overall goal was to reduce significantly the total firing time and thus enhance the seismic energy generated by the detonation of explosives. It could have a positive effect on the level of paraseismic vibrations, and thereby improve the efficiency of rockburst prevention by using the phenomenon of seismic wave interference. Since the production blasting cannot have a negative impact on the mining process, the influence of the shorter delay sequences on the output fragmentation, muck pile shape and advance was analysed.

\section{Material and methods}

Underground tests were conducted in selected workings of SI-V/6 mining panel of the Polkowice-Sieroszowice mine. The analysis covered 4 full-sized mining faces, two of which were fired using regular drilling and firing pattern employed in this area, with a total firing time of 3,000 ms (face A and B), while the other two were blasted using the modified pattern with the total firing time of $475 \mathrm{~ms}$ (face $\mathrm{C}$ and D). It means, that firing time has been reduced by over six times. The faces were fired during production blasting, after the $4^{\text {th }} \mathrm{shift}$, along with a series of 5 other faces. The geometry of mine workings and location of considered faces is presented in figure 3 .

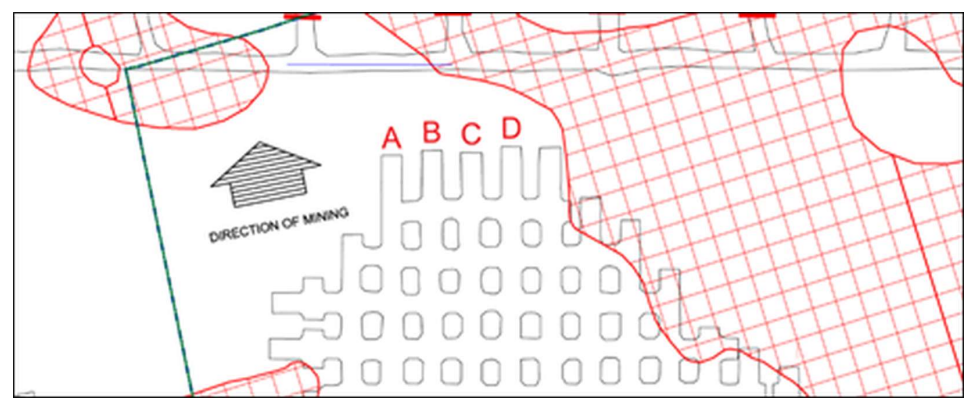

Fig. 3. Geometry of workings and location of tested faces.

The ore body in the area of trials was composed of three rock stratum, including sandstone at floor level, shale in the middle and dolomite in the upper part, with thicknesses of approximately $50 \mathrm{~cm}, 30 \mathrm{~cm}$ and $120 \mathrm{~cm}$ respectively. The approximate width of the analysed faces was $4.5 \mathrm{~m}$ by the floor, $6.0 \mathrm{~m}$ by the roof and the height of $2.0 \mathrm{~m}$ (fig. 4). The average uniaxial compressive strength $R_{c}$ of the ore body rocks was $115 \mathrm{MPa}$. 


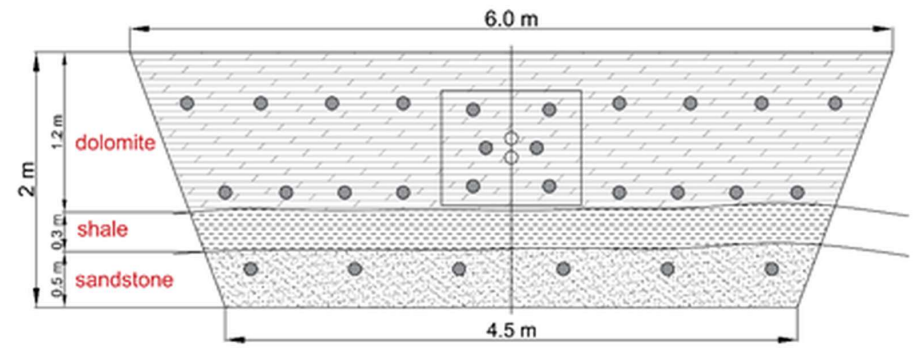

Fig. 4. Dimensions of the mining face and the blasthole locations within different geological stratum.

The locations of the blastholes in the faces, as well as the amount of explosives loaded into individual blastholes, were exactly the same for all the analysed cases. All blastholes length was $3.0 \mathrm{~m}$ and diameter of $48 \mathrm{~mm}$. The bottom row of 6 holes was located in sandstone stratum. Other holes were drilled in dolomite (no holes in shale). The drilling pattern with parallel cut with two empty holes was applied. The total number of blastholes in each face was 30 , including two empty holes. In each case, the Emulinit $8 \mathrm{~L}$ bulk emulsion explosive was loaded into the blastholes, $102 \mathrm{~kg}$ per face, with a density of $1.1 \mathrm{~g} / \mathrm{cm}^{3}$ in the moment of firing and nominal detonation velocity of $3,800 \mathrm{~m} / \mathrm{s}$. The detailed delays, sequences, geometry of blastholes and the masses of explosives in individual holes for blasting using standard and modified patterns are presented in figure 5. The upper digits by the blastholes is the firing sequence, while the lower - the delay time in milliseconds.
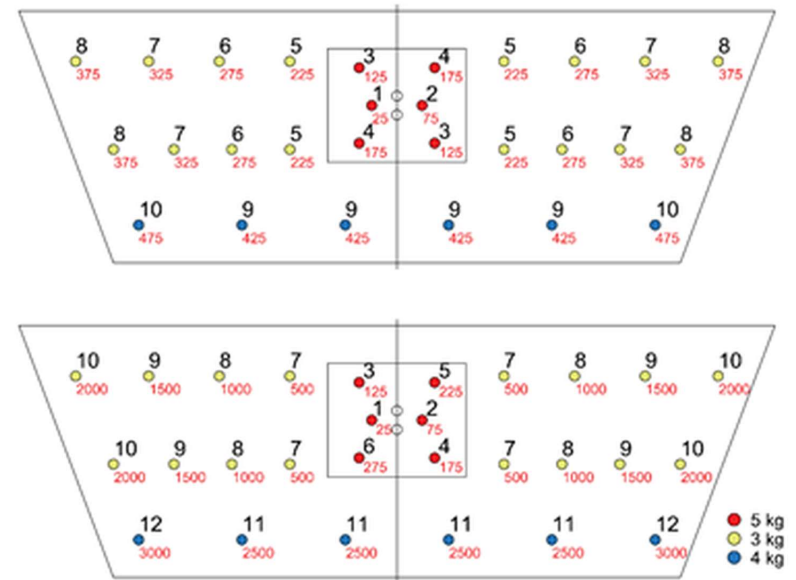

Fig. 5. The regular (top) and modified (bottom) drilling and firing pattern applied for tests.

Two types of non-electric detonators were used:

- Nitronel LP (long period) with a delay interval of $500 \mathrm{~ms}$,

- Nitronel MS (milliseconds) with a delay interval of $25 \mathrm{~ms}$.

Both contain $0.6 \mathrm{~g}$ PETN. The shock tubes were initiated using the detonating cord, which in turn was initiated using a Nitroconnector cord set equipped with an electric detonator connected to the main blasting network.

The effects of blasting were analysed based on a visual examination of the muck pile shape, an advance assessment performed using a laser measure and degree of fragmentation in rock breakage based on photographic documentation. The evaluation of rock fragmentation was conducted based on digital imaging to determine the fragment size distribution using the WipFrag software [23]. The methodology of this kind of measurements consists of the following steps: (1) taking a representative set of pictures for individual cross- 
sections of the output, (2) reviewing and selecting photos for further analysis, (3) analysis using a computer program and finally (4) determining a size distribution curve. Since the quality of the photos is essential for the appropriate analysis of the output fragmentation, they were taken using additional high-power LED light. A loader with a bucket capacity of 2,5 $\mathrm{m}^{3}$ was used to haulage the excavated rocks. The total volume of the output in a single face was estimated to be approximately $35 \mathrm{~m}^{3}$. In order to obtain reliable data, the pictures of the excavated rocks were taken immediately after each bucket was collected. Due to the difficult underground work environment, which may influence the quality of the photos, an appropriately greater number of pictures were taken. During the next step, the representative series of photos were selected for each analysed mining face. As a result of the tests, size distribution curves were determined for the excavated rocks, including the contents of individual fractions in the muck piles.

\section{Experimental section}

Taking pictures of the excavated rocks began after approximately 90 minutes following the completion of mining faces firing, which was required for a good test site ventilation and removal of post-blast fumes. During the hauling of the output from the analysed faces, a total of 90 pictures were taken, including 22 for face A and 21 for face B, where regular drilling and firing pattern were applied, and 23 for face $\mathrm{C}$ and 24 for face $\mathrm{D}$, blasted using modified patterns. A view of the mining faces after the firing is presented in figures 6 and 7.
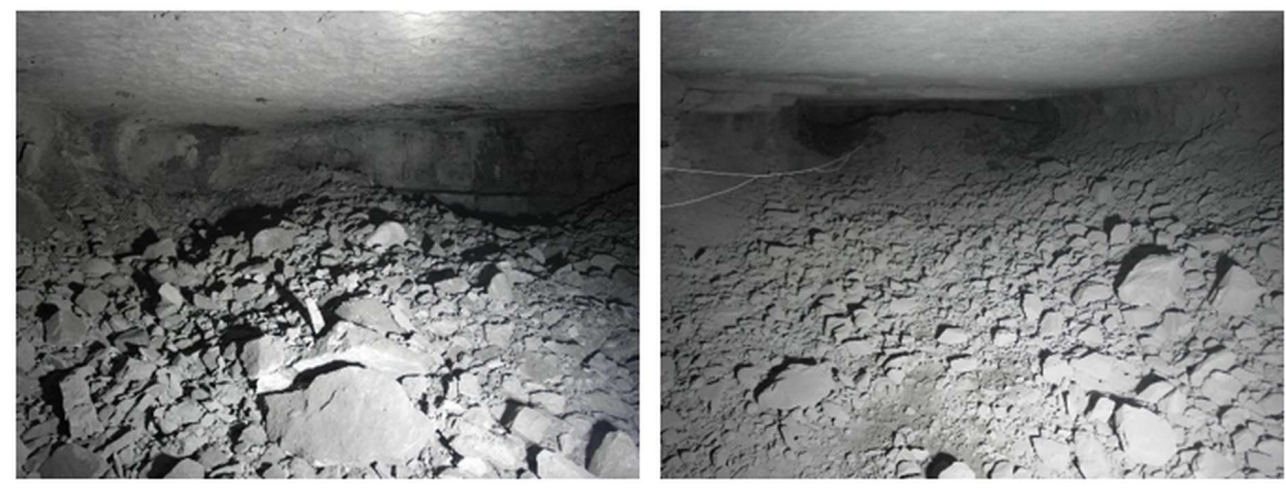

Fig. 6. View of the mining faces after blasting using regular drilling and firing pattern: face A (left) and face $\mathrm{B}$ (right).
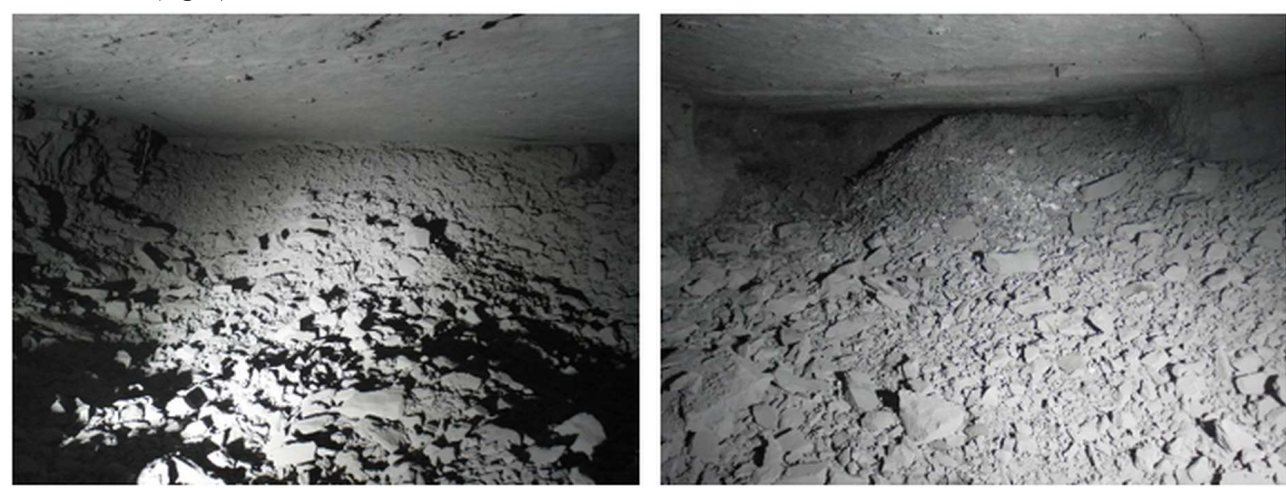

Fig. 7. View of the mining faces after blasting using modified drilling and firing pattern: face $\mathrm{C}$ (left) and face $\mathrm{D}$ (right). 
Due to the quality of the pictures, 4 series of 20 pictures each were selected for further analysis.

The muck pile shape was evaluated prior to the excavating of the rocks. It was found that the muck piles obtained as a result of firing using modified patterns were relatively flat and distributed over a length of approximately $25 \mathrm{~m}$ from the mining face. The average height of the muck pile was approximately $1 \mathrm{~m}$. In the case of the other two faces, where regular patterns were applied, the muck piles were more and exhibited much more regular shape. They were distributed over a length of approximately $10 \mathrm{~m}$ from the mining face, whereas their maximum height did not exceed ca. $1.5 \mathrm{~m}$. Figure 8 shows the profiles through a muck piles from a blasting using considered patterns.

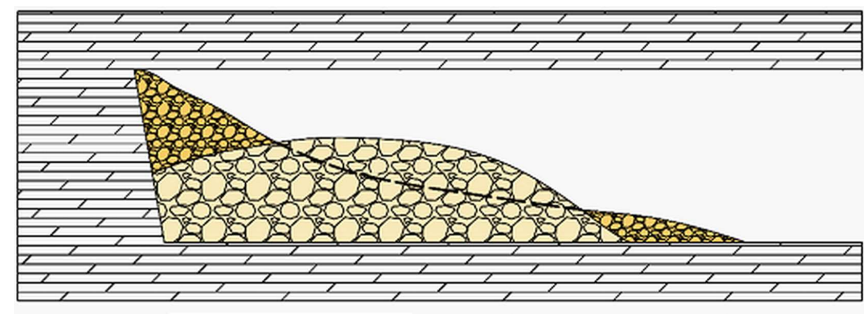

EgEg modified patlen

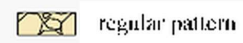

Fig. 8. Profiles through a muck piles after firing using the analysed blasting patterns.

Afterwards, the grain size distribution curves were obtained for the considered drilling and firing patterns, based on the image analysis. The evaluation was carried out separately for each tested mining face. Results of analysis in the form of rock fragmentation curves for faces $\mathrm{A}, \mathrm{B}, \mathrm{C}$ and $\mathrm{D}$ fired using different blasting patterns are presented in table 1 . The obtained grain size distribution curves and histograms indicate a lack of significant differences in terms of fine fractions. In the case of face A, a minor difference can be observed in the slit fraction content, as well as a slightly higher content of the fractions greater than $681 \mathrm{~mm}$. Nevertheless, the sizes and percentage contents of the rock fragments for both faces fired using regular blasting pattern (face $\mathrm{A}$ and $\mathrm{B}$ ) are similar.

The grain size distribution curves and histograms obtained for the modified firing patterns demonstrate a slight difference in the content of the individual fractions, which may have resulted in the heterogeneity of the rock mass. The content of the remaining fractions is similar.

\section{Results and discussion}

A direct comparison of the rock fragmentation in faces fired using regular and modified blasting patterns shows no difference in the content of slit fractions. In the case of the modified patterns, considerably higher content of fraction below $100 \mathrm{~mm}$ can be observed (fig. 9) and amounts to approximately $20 \%$. Finally, it was concluded, that reducing of the total face firing time resulted in the lowering of the content of the fractions greater than 316 $\mathrm{mm}$. 
Table. 1. Cumulative fragment size distribution curve and histogram for considered cases.

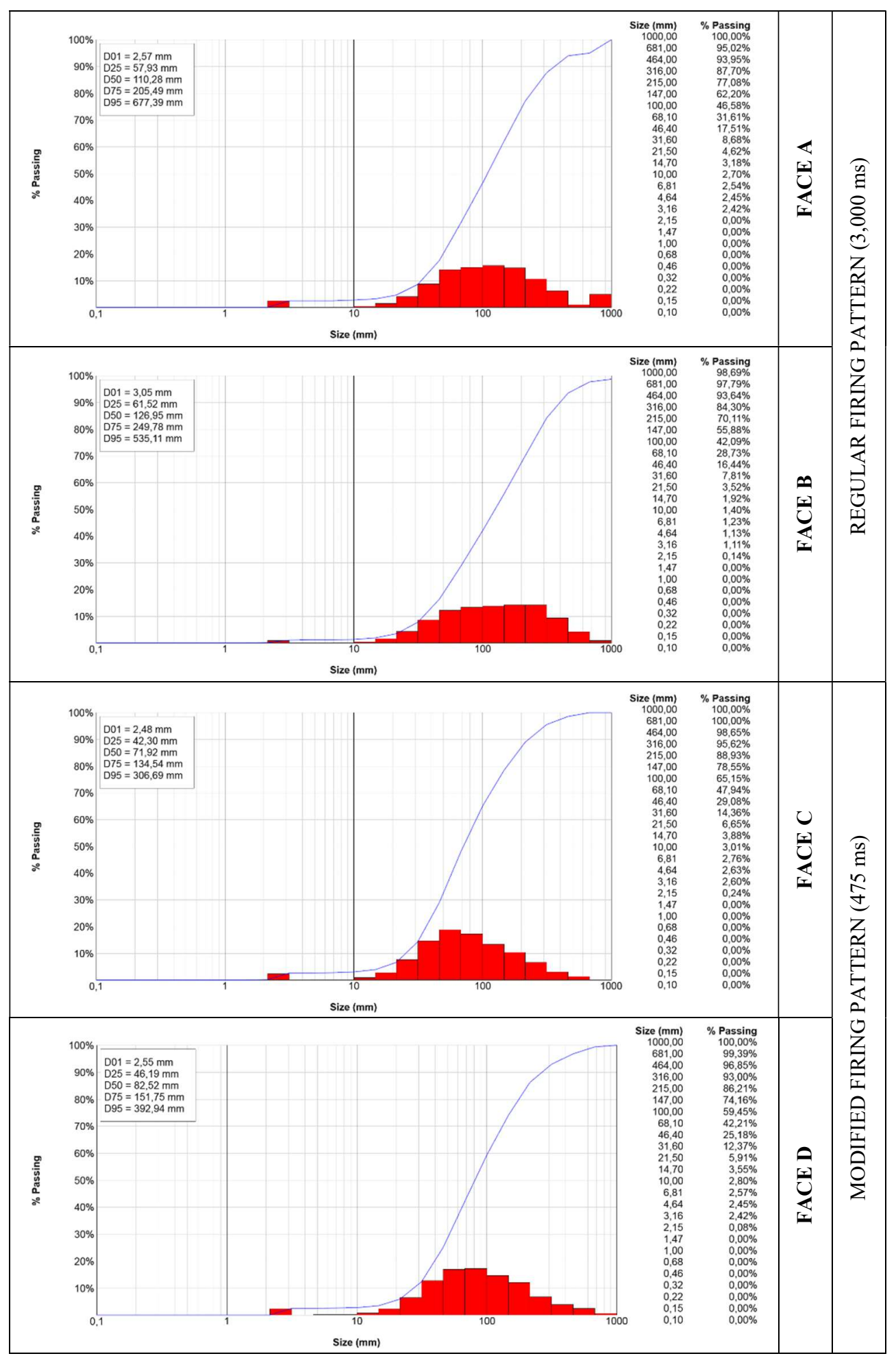




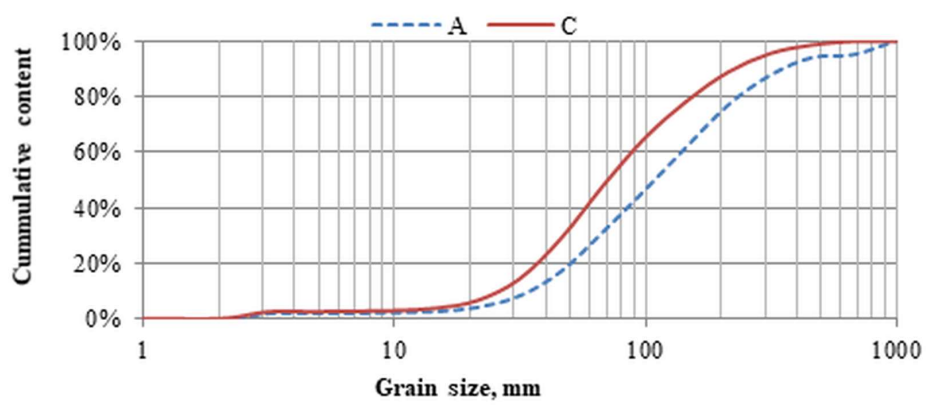

Fig. 9. Comparison of grain size distribution curves obtained for faces A and C fired using different blasting patterns.

The limit dimensions of grains obtained from firing of individual mining faces are presented in table 2 . For fraction D75, for which $75 \%$ of the particles in the output are smaller, the average rock fragment size for regular pattern amounted to $205 \mathrm{~mm}$ (face A) and $249 \mathrm{~mm}$ (face B) and was greater than the average fragment size for modified firing pattern by 86 $\mathrm{mm}$, on average.

Table 2. The average grain sizes for the analysed faces.

\begin{tabular}{|c|c|c|c|c|}
\cline { 2 - 5 } \multicolumn{1}{c|}{} & \multicolumn{4}{c|}{ Grain size [mm] } \\
\cline { 2 - 5 } & \multicolumn{2}{c|}{ regular pattern } & \multicolumn{2}{c|}{ modified pattern } \\
\cline { 2 - 5 } & face A & face B & face C & face D \\
\cline { 2 - 5 } & \multicolumn{4}{|c|}{} \\
\hline D01 & 2.57 & 3.05 & 2.48 & 2.55 \\
\hline D25 & 57.93 & 61.52 & 42.30 & 46.19 \\
\hline D50 & 110.28 & 126.95 & 71.92 & 151.75 \\
\hline D75 & 205.49 & 249.78 & 134.54 & 392.94 \\
\hline D95 & 677.39 & 535.11 & 306.69 & \\
\hline
\end{tabular}

After the full removal of blasted rocks from the mining faces, the achieved advance was determined. For this purpose, the distance from the face line before firing to the current face position was measured. No significant differences were observed for all four analysed cases in terms of the achieved advance, which ranged from $2.9 \mathrm{~m}$ to $3.0 \mathrm{~m}$, what indicates an adequate and satisfactory value from the mining efficiency point of view, as it is more than $95 \%$ of the assumed advance.

\section{Conclusions}

The performed blasting work efficiency analysis with the use of different blasting patterns indicates, that the modifications related to the reducing of the face firing time do not cause significant differences in terms of the appropriate excavation of the mining face, including the length of face advance and the degree of rock fragmentation. The face advances achieved when using modified firing patterns were correct and did not deviate from blasted using the regular patterns applied in considered mining panel. Similar conclusions can be drawn from the fragmentation analysis, which was basically characterised by a higher content of fine fractions. However, such a situation may have a positive influence on further steps of the production process, as it may result in a reduction of the costs related to the mechanical crushing of rocks. It should also be noted, that crushing of the rocks using explosives is 
considerably cheaper than when using mechanical crushers, mostly due to high power consumption. Therefore, energy savings may have a positive economic effect on the entire ore enrichment process.

One of the negative effects of a shorter face firing sequence is greater flyrock range from the mining face, which slightly complicates and extends the excavating process. Despite the fact, that the scope of the research included the firing of four faces only, the obtained results confirmed the right direction of further investigations concerning the modification of commonly used production blasting in terms of adapting the applied drilling and firing patterns in order to improve the efficiency of rock burst prevention.

The obtained results confirmed the possibility of implementing substantial changes in the firing patterns in terms of modifying the total face firing time, which in the considered cases was reduced by over six times, i.e. from 3,000 ms to $475 \mathrm{~ms}$. It can also be assumed that such a significant reduction of the firing time will allow for the further multiplication of the source of vibrations by the simultaneous firing of a greater number of mining faces with reduced initiation times. As a result, this can lead to paraseismic wave interference and ultimately improve the efficiency of currently applied rock burst prevention methods, which are carried out mainly as a group distressing blasting. It must also be mentioned that these types of blasting pattern modifications are relatively easy to implement and do not generate additional costs since the number of blastholes and the quantities of the used explosives are exactly the same as in the case of standard drilling and blasting patterns. Furthermore, they do not disrupt the currently applied technology of blasting works. In order to provide a more detailed analysis of the influence of blasting patterns on the propagation of paraseismic waves and the possibility to amplify purposely the energy of rock mass vibration within the area which is indicated as potentially instable, this issue would also need to be investigated from the seismic point of view.

This paper has been prepared through the Horizon 2020 EU project on "Sustainable Intelligent Mining Systems (SIMS)", Grant Agreement No. 730302

\section{References}

1. J. Hudyma, Australian Centre for Geomechanics (AMS, Sidney, 2004)

2. S. Townend, A. Sampson-Forsythe, Int. Conf. Deep High Stress Min., 1, 65-77 (2014)

3. Z. Wen, X. Wang, Y. Tan, H. Zhang, W. Huang, Q. Li, Shock Vib., 2016, 1-9 (2016)

4. J. Butra, J. Kudełko, Cuprum, 4:61, 5-20 (2011)

5. Z. Ouyang, Q. Qi, S. Zhao, B. Wu, N. Zhang, Shock Vib., 2, 1-7 (2015)

6. P. Konicek, K. Soucek, L. Stas, R. Singh, Int. J. Rock Mech. Min. Sci., 61, 141-153 (2013)

7. Ł. Wojtecki, P. Konicek, J. Schreiber, J. Rock Mech. Geotech. Eng., 9, 694-701 (2017)

8. M.R. Saharan, H. Mitri, Procedia Eng., 26, 37-47 (2011)

9. H. Manchao, Z. Xiaohu, Z. Shuai, Procedia Eng., 191, 89-97 (2017)

10. M.F. Boler, L.P. Swanson, Bureau of Mines (1993)

11. A. Sainoki, M.Z. Emad, H. Mitri, Can. Geotech. J., 54 (4), 518-528 (2017)

12. I. Vennes, H. Mitri, J. Rock Mech. Geotech. Eng., 9, 1085-1093 (2017)

13. M. Kempin, A. Sprague, S. Narendranathan, A.P. Mikula, M.F. Lee, Proc. Int. Conf. Deep High Stress Min., 97-110 (2007)

14. J. Butra, W. Pytel, Proc. Int. Conf. Deep High Stress Min., 187-198 (2010) 
15. Z. Burtan, E3S Web Conf., 24, 01004 (2017)

16. T. Machoń, Przegląd Górniczy, 12, 81-88 (2013)

17. K. Fuławka, W. Pytel, P. Mertuszka, J. Sust. Min., 17, 1-10 (2018)

18. W. Pytel, P. Mertuszka, B. Cenian, Proc. Int. GeoConference SGEM, 1, 353-360 (2015)

19. Z. Kłeczek, Górnictwo i Geoinżynieria, 28:3/1, 153-159 (2004)

20. A. Zorychta, J. Cieślik, Z. Burtan, D. Chlebowski, Cuprum, 3:76, 83-93 (2015)

21. P. Mertuszka, W. Pytel, K. Szczerbiński, Proc. World Mining Congress, 1, 355-366 (2016)

22. J. Kabiesz, A. Lurka, J. Drzewiecki, Arch. Min. Sci., 60:3, 807-824 (2015)

23. WipFrag 3 Manual (AMS, Sidney, 2019) 